\title{
Amplification of viral RNA for the detection of dengue types $I$ and 2 virus
}

\author{
Chia C. Pao, ${ }^{\star} \ddagger$ Ding-Shyan Yao, ${ }^{\star}$ Chieh-Yu Lin ${ }^{\star}$ \\ and Chwan-Chuen King $\dagger$ \\ * Department of Biochemistry, Chang Gung Medical College and $\dagger$ Institute of \\ Public Health, National Taiwan University School of Medicine, Taipei, \\ Taiwan, Republic of China
}

Accepted for publication I 7 fuly I99I

\begin{abstract}
Summary
In vitro DNA amplification by means of the polymerase chain reaction (PCR) was used to amplify dengue types I and 2 viral genomes in cultured cells and in the serum of persons infected with dengue virus. Results of the present investigation suggest that the PCR method is type-specific in detecting dengue virus and has a detection sensitivity of less than Ioo plaque-forming units (pfu) for both serotypes of the virus. The PCR method may be useful for detecting and typing dengue virus in clinical and epidemiological specimens.
\end{abstract}

\section{Introduction}

Dengue viruses are members of the family Flaviviridae (flaviviruses) which consists of over 60 viruses and they are known to infect human beings. The diseases caused by dengue virus infection range from non-descript febrile illness and dengue fever to dengue haemorrhagic fever (DHF) and the more serious dengue shock syndrome (DSS) in endemic areas where more than one serotype may exist. ${ }^{1,2}$ Dengue fever is probably the most important tropical arthropod-borne viral disease of human beings. Large epidemics may involve up to several million people resulting in a major public health problem. Because of the increased incidence of both dengue fever and DHF/DSS, a simple and reliable method for rapid and accurate diagnosis of dengue virus infection is needed.

Serological and immunological methods for the diagnosis of dengue virus infection include haemagglutination inhibition (HI) and plaque-reduction neutralization (PRN) tests as well as IgM-capture ELISA. Direct detection of dengue viruses depends on their isolation in susceptible cell lines or mosquitoes followed by their identification with specific antibodies. ${ }^{3-5}$ Recently, DNAbased hybridisation techniques have also been used for detecting and typing dengue viruses with some success. ${ }^{6,7}$

DNA amplification by means of a polymerase chain reaction (PCR) is a recent development which has expanded the research and diagnostic applications of molecular biology. PCR is a simple and elegant method that offers rapidity and incredible sensitivity through in vitro amplification of target nucleotide sequences. ${ }^{8,9}$ We report here the results of using PCR to detect

$\ddagger$ Address correspondence to: Professor Chia C. Pao, Chang Gung Medical College, Department of Biochemistry, 259 Wen Hwa Road, KweiShan, TaoYuan, Taiwan, Republic of China. 
dengue type I (DEN-I) and type 2 (DEN-2) viruses which have recently caused localised infections in Taiwan.

\section{Materials and methods}

\section{Viruses}

C6/36 Aedes albopictus cells (Hawaii clone) were kindly provided by Dr May Chu of the Division of Vector-Borne Infectious Diseases, Centres for Disease Control, Fort Collins, CO, U.S.A. The cells were grown as a monolayer with Dulbecco's minimal essential medium supplemented with $5 \%$ fetal calf serum, IOO units $/ \mathrm{ml}$ penicillin, Io0 $\mu \mathrm{g} / \mathrm{ml}$, streptomycin, and $25 \mu \mathrm{g} / \mathrm{ml}$ amphotericin B (GIBCO, Grand island, NY, U.S.A.). DEN-I and DEN-2 viruses, isolated from patients, were passaged once in monkeys and then inoculated into Toxorhynchites amboinensis. The infected $T$. amboinensis were ground, filtered and then passaged once in LLC-MK2 cells, three times in Vero E6 cells and finally inoculated into $\mathrm{C} 6 / 36 \mathrm{H}$ cells at a multiplicity of infection of approximately 0.01 . Dengue viruses were recovered from the $\mathrm{C} 6 / 36 \mathrm{H}$ cells on the eighth day after inoculation. The yields were approximately $7.5 \times 10^{6}$ plaque-forming units (pfu) per $\mathrm{ml}$ for DEN-I and $I .5 \times 10^{7} \mathrm{pfu} / \mathrm{ml}$ for DEN-2. Viral RNA was partly purified by direct phenol and chloroform extraction followed by lithium chloride precipitation before being used for PCR. ${ }^{10}$

\section{Serum samples}

A sample of serum was obtained, after informed consent, from each of five patients $I-5$ days after the onset of dengue fever. The samples were stored at $-80{ }^{\circ} \mathrm{C}$ before being used for serological confirmation of dengue virus infection by direct fluorescent antibody staining and for the detection of dengue viruses by PCR. Viral nucleic acid was extracted from the serum and purified by means of a mixture containing $50 \mu 1$ serum, $25 \mu 1$ ribonuclease inhibitor, vanadyl-ribonuclease complex ( $200 \mathrm{mM}$, purchased from BRL), $5 \mu 1$ carrier transfer RNA $(2.5 \mu \mathrm{g} / \mu \mathrm{l}$, purchased from Sigma Chemicals Inc) and I $70 \mu \mathrm{l}$ sterile distilled water with $250 \mu \mathrm{l}$ water-saturated phenol. Purified nucleic acid was then recovered by ethanol precipitation before being subjected to PCR analysis.

\section{Primers and probes}

Oligonucleotides were synthesised from previously described viral sequences so as to serve as primers for PCR. ${ }^{11,12}$ The sequences of these oligonucleotides have been compared with other previously described flavivirus sequences so as to ensure non-homology. The sequences of the primers and lengths of flanking DNA are shown in Table I. Oligonucleotides complementary to internal segments of the amplified sequences were also synthesised and used as probes in Southern blot hybridisation analysis. These oligonucleotides were end-labelled with [gamma- ${ }^{32} \mathrm{P}$ ]ATP and $\mathrm{T}_{4}$ polynucleotide kinase to approximately $\mathrm{I} \times 10^{6} \mathrm{cpm}$ per pmole before their use as probes. $^{13}$ The sequences of the probes for DEN-I and DEN-2 are CCTGCCGTCCTGCGCAAACTGTGCATTGAAGCTAAAATAT and 
Table I Primers for amplifying dengue virus by the polymerase chain reaction

\begin{tabular}{llc} 
& Dengue virus type I & Dengue virus type 2 \\
\hline Primers $\left(5^{\prime}-3^{\prime}\right)$ & & \\
Anti-sense & CAACCATTGCCC- & GAAATGTGTCGT- \\
& CAGCCTCTGTCC & TCCTATGGTGTA \\
Sense & CTTGGTCTAGAA- & GTAACTTATGGG- \\
& ACAAGAACCGAA & ACGTTACCACC \\
Flanking length & 5I2 bp & 225 bp \\
Gene encoded & M protein & Envelope protein E \\
Sizes after & 316 and I96 bp & I24 and roI bp \\
HaeIII digestion & & \\
\hline
\end{tabular}

Lengths of amplified dengue virus nucleotide sequences after restriction endonuclease HaeIII treatment were calculated from known nucleotide sequences of the viral genome and the locations of the restriction endonuclease sites.

$\mathrm{bp}=$ Base pairs.

\section{GGAATGGGACTGGAGACACGAACTGAAACATGGATGTCAT, respectively.}

\section{Reverse transcription of viral RNA}

For the first-strand cDNA synthesis by reverse transcription, a mixture was prepared containing RNA purified from either virus or serum samples, IOO pmoles antisense primer, $50 \mathrm{mM}$ Tris hydrochloride buffer $\mathrm{pH} 8.3,75 \mathrm{mM}$ potassium chloride and $3 \mathrm{~mm}$ magnesium chloride. This mixture was heated for Io min in a $95^{\circ} \mathrm{C}$ water bath and cooled rapidly on ice. cDNA synthesis was achieved after the mixture had been adjusted to contain I 5 nmoles each of the four deoxyribonucleoside triphosphates, 20 units of ribonuclease inhibitor (BRL, Gaithersburg, Maryland, U.S.A.), and 200 units of cloned Moloney murine leukaemia virus (MMLV) reverse transcriptase (BRL, Gaithersburg) in a final volume of $30 \mu \mathrm{l}$, which was then incubated at $42{ }^{\circ} \mathrm{C}$ for $30 \mathrm{~min}$. The cDNA was stored at $-20^{\circ} \mathrm{C}$ before being used for amplification.

\section{Nucleic acid amplification by the polymerase chain reaction (PCR)}

PCR amplification of cDNA was performed with thermostable Taq DNA polymerase in a Perkin-Elmer Cetus Thermal Cycler (Perkin-Elmer Cetus, Norwalk, CT, U.S.A.) The $100 \mu 1$ amplification reaction mixture contains IO $\mathrm{mM}$ Tris hydrochloride buffer $\mathrm{pH} 8.3$; $50 \mathrm{~mm}$ potassium chloride; $\mathrm{I} \cdot 5 \mathrm{~mm}$ magnesium chloride; $0.01 \%$ gelatin; $20 \mathrm{pM}$ each of the two oligonucleotide primers; 2.5 nmoles each of the four deoxyribonucleoside triphosphates; 1 unit of Taq DNA polymerase (Perkin-Elmer Cetus, Norwalk) and cDNA prepared from the reverse transcription of putative dengue viral genome. The temperature of the reaction mixture was first raised to $94^{\circ} \mathrm{C}$ for $\mathrm{I}$ min to denature the DNA, then cooled to $63^{\circ} \mathrm{C}$ for 2 min to allow annealling of primers to putative target DNA sequences. This procedure was followed by raising the temperature to $72{ }^{\circ} \mathrm{C}$ for $3 \mathrm{~min}$ in order to extend the DNA chain. The whole process was repeated $3 \mathrm{I}$ times with a final period of incubation at 
$72{ }^{\circ} \mathrm{C}$ for $10 \mathrm{~min}$. A $15 \mu 1$ volume of the amplified reaction mixture was separated by electrophoresis in a $2.5 \%$ agarose gel. The DNA in the agarose gel was visualised by means of UV light after ethidium bromide staining and then transferred on to nitrocellulose membrane filters for Southern blot hybridisation analysis.

\section{Southern blot hybridisation}

Southern blot hybridisations were performed according to published procedures ${ }^{13,14}$ with the following modifications: after hybridisation, each filter was washed sequentially in $2 \times S S C$ (I $\times$ SSC is $0.15 \mathrm{M}$ sodium chloride and $0.015 \mathrm{M}$ sodium citrate) and $0 . \mathrm{I} \%$ sodium dodecyl sulphate twice for IO min at room temperature; and then in $0 . \mathrm{I} \times \mathrm{SSC}$ and $0 . \mathrm{I} \%$ sodium dodecyl sulphate three times for $15 \mathrm{~min}$ at $55^{\circ} \mathrm{C}$. The sequences of the oligonucleotide probes used in Southern blotting are listed in Table I. Restriction endonucleases were purchased from Boehringer Mannheim (Mannheim, Germany).

\section{Precautions against contamination and false-positive results in PCR}

Because of the high degree of amplification of the PCR procedures, special precautions were taken to minimise sample-to-sample contamination and PCR-product carry-over in order to avoid false-positive results. These measures included the separate dispensing of all reagents, physical separation of pre- and post-PCR reactions, and meticulous laboratory techniques. Furthermore, all reagents were irradiated with UV light so as to inactivate any double-stranded DNA which may have been present before sample DNA was added and the PCR started. ${ }^{15}$ As a negative control, $50 \mu \mathrm{g}$ human DNA or I $\mu \mathrm{g}$ Escherichia coli DNA was included in each assay and always yielded negative results. Multiple reagent controls were also included in each PCR assay and gave negative results. Repeated DNA amplification assays performed on the same specimens at different times produced the same results.

\section{Results}

Plate I shows the amplification of dengue virus RNA after viral RNA genome was first converted to $C D N A$ by reverse transcription with MMLV reverse transcriptase. The DEN-I and DEN-2 positivity were indicated by the presence of 5 12 base pairs (lane 2) and 225 base pairs (lane 3) DNA, respectively. Based on the number of plaque-forming units in the virus preparation, the sensitivity of detection by PCR was estimated to be $<100 \mathrm{pfu}$ for either type of dengue virus. The primers used in this study do not cross amplify human DNA or Japanese encephalitis virus which belongs to the same flavivirus family and is often prevalent in the same geographical area (Plate I, lanes 4 and 5 ).

The authenticity of the amplified DNA was established by two independent methods. First, the amplified putative dengue virus DNA was subjected to restriction endonuclease analysis. When the amplified DEN-I and DEN-2 DNA were treated with restriction endonuclease HaeIII, the original 512 (Plate 2, lane 2) and 225 (Plate 2, lane 5) base pair DNA disappeared and were 


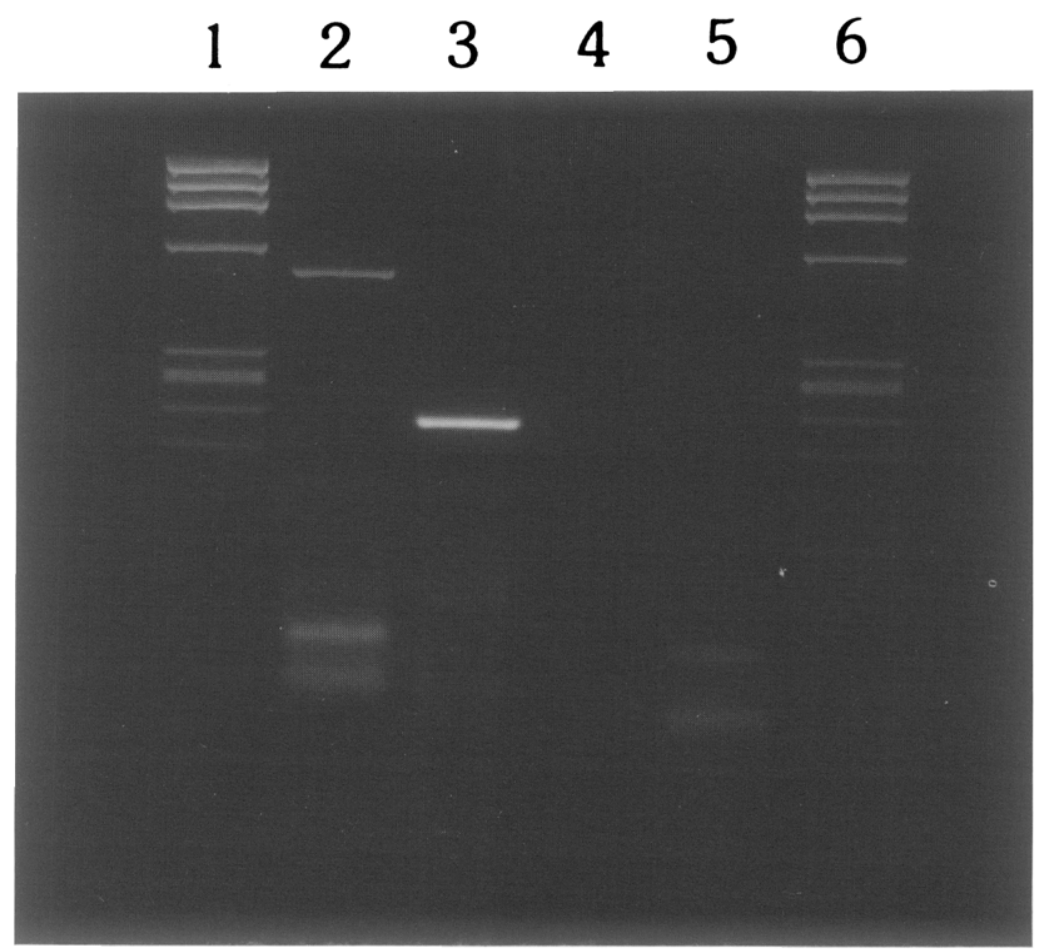

Plate I. Agarose gel analysis of dengue virus-specific PCR amplification. Primers used and the lengths of nucleotide sequences amplified are listed in Table I. HaeIII-digested PhiX-I74 DNA are used as DNA size standards in lanes 1 and 6 . The sizes are (from top to bottom) I353; 1078;872;603;310;281, 271; 234; I94; I 8 and 72 base pairs. Lanes 2 and 3 relate to amplified products of dengue virus types I and 2 RNA, respectively. Lanes 4 and 5 relate to human DNA and Japanese encephalitis virus RNA, respectively. DNA bands on the bottom of the gel are primer-dimers. 

1
2
3
4
5
6
7
8

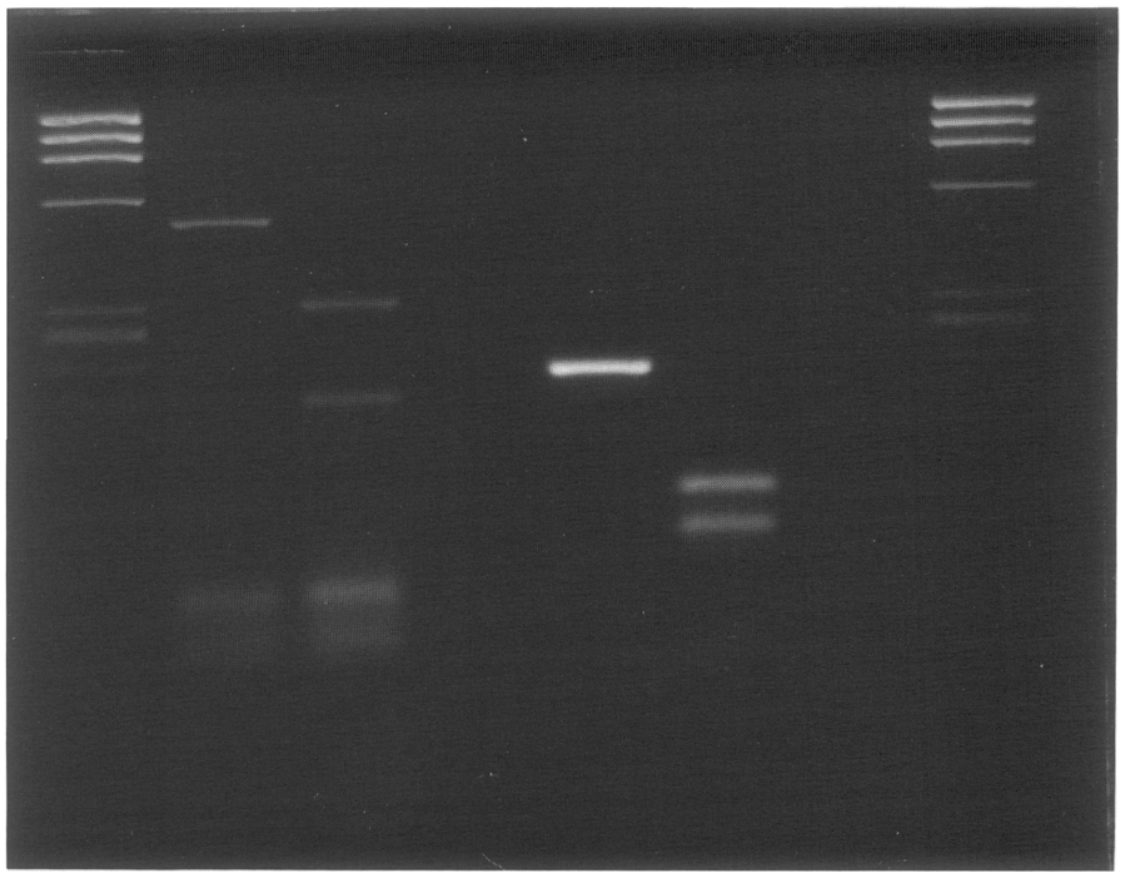

Plate 2. Agarose gel electrophoresis of amplified dengue virus nucleotide sequences before and after restriction endonuclease digestion. Conditions for restriction endonucleases HaeIII digestion are those recommended by the enzyme manufacturers. Calculated lengths after HaeIII digestion are listed in Table I. Lanes $\mathbf{I}$ and 8 are restriction endonuclease HaeIIIdigested phage Phi-X I74 DNA used as DNA size standard. The sizes are (from top to bottom) I353, 1078, 872,603,310, 281, 27I, 234, I94, I I 8 and 72 base pairs. Lanes 2 and 3 are amplified dengue virus type $\mathbf{I}$ before and after restriction endonuclease HaeIII digestion, respectively. Lanes 5 and 6 are amplified dengue virus type 2 before and after restriction endonuclease HaeIII digestion, respectively. Lanes 4 and 7 are blanks. 

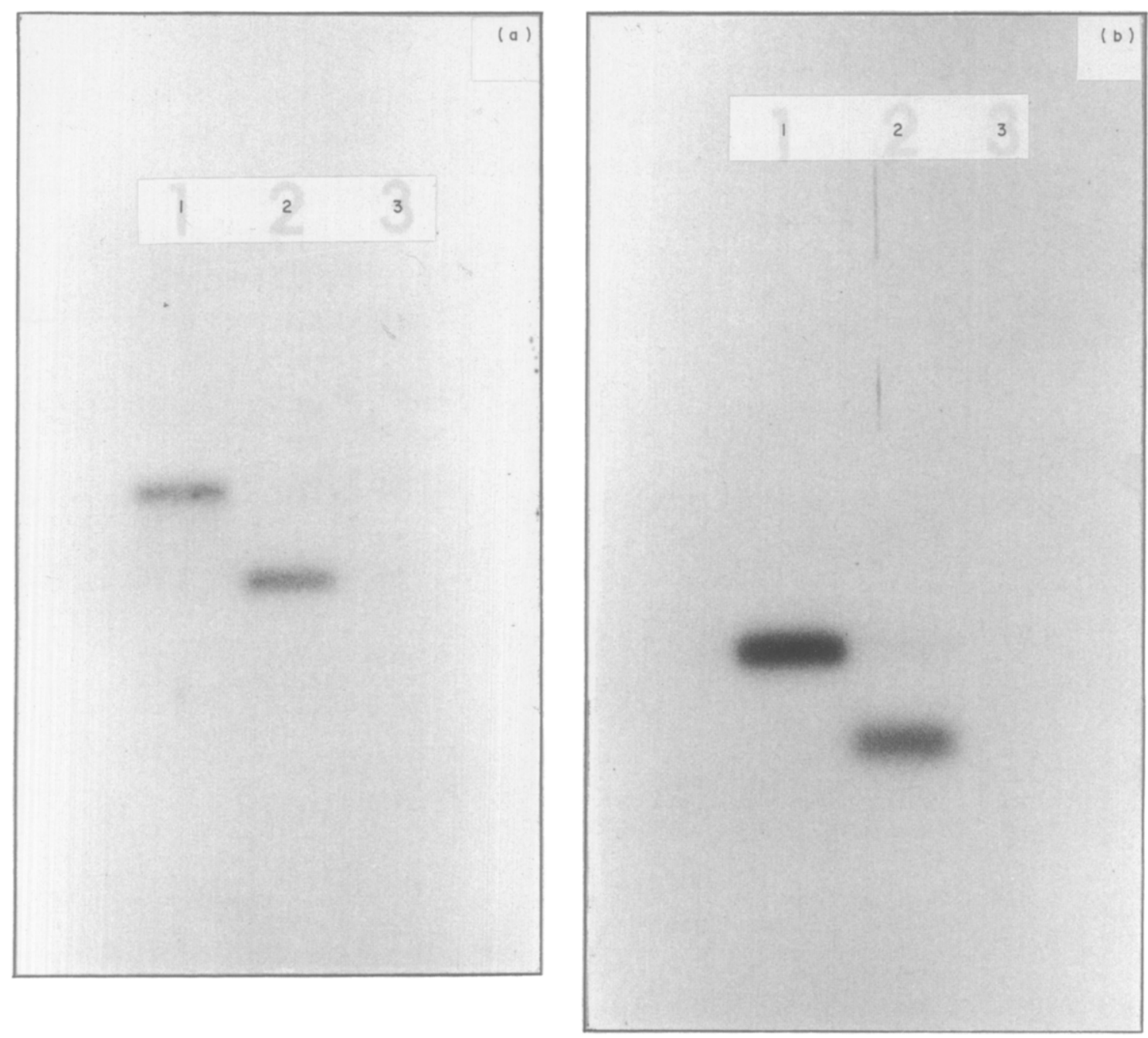

Plate 3. Autoradiographs of Southern blot hybridisation tests of amplified dengue virus type I (a) and dengue virus type 2 (b) DNA with internal oligonucleotide probes. Lanes $I$ in both (a) and (b) are undigested and lanes 2 are hybridisation of HaeIII-digested amplified dengue virus with internal oligonucleotide probes, respectively. Lanes 3 in both panels are blanks. Probe sequences are indicated in Table I. The exposure time was $2 \mathrm{~h}$ for (a) and $20 \mathrm{~min}$ for (b) at room temperature without an intensifying screen. 
Table II Detection and typing of dengue viruses by direct fuorescent antibody (FA) staining and by the polymerase chain reaction (PCR)

\begin{tabular}{cll} 
Specimen & \multicolumn{1}{c}{$\begin{array}{c}\text { By direct } \\
\text { FA staining }\end{array}$} & \multicolumn{1}{c}{ By } \\
\hline PCR
\end{tabular}

replaced with DNA of 316 and I96 (Plate 2, lane 3) and of I24 and IoI base pairs (Plate 2, lane 6), respectively. The sizes of DNA fragments resulting from the actual restriction endonuclease digestion matched exactly with those calculated from known viral genome nucleotide sequences and locations of restriction sites.

Secondly, amplified dengue virus DNA was analysed by Southern blot hybridisation with internal oligonucleotide probes complementary to nucleotide sequences located between the two primers. Results indicated that amplified DNA from each type of dengue virus hybridised only with its own homologous probe [lanes $I$ in both (a) and (b) of Plate 3].

Furthermore, Southern blot hybridisation showed that the 316 base pair and 124 base pair DNA fragments, resulting from HaeIII digestion of amplified DEN-I and DEN-2, hybridise with their respective oligonucleotide probes [lanes 2 in (a) and (b) of Plate 3]. These results also confirmed the locations of HaeIII restriction sites with respect to the locations of viral sequences that are complementary to the oligonucleotide probes.

The detection and typing of dengue viruses by FA staining in five serum samples, obtained from patients during the acute phase of infection, was compared with their detection by the PCR method. The results are shown in Table II.

\section{Discussion}

Dengue presents a major public health problem and is probably the most important arthropod-borne viral disease in terms of human morbidity and mortality. ${ }^{1}$ The increasing incidence and transmission of dengue viruses indicate the need for a rapid and reliable method for detecting and identifying the serotypes of dengue viruses. Serological and immunological assays, such as HI, PRNT or ELISA, are widely used in the laboratory diagnosis of dengue virus infections and in sero-epidemiological surveys. HI tests and ELISA, however, are often complicated by the presence of highly cross-reactive antiflavivirus antibodies and often are not dengue type-specific. ${ }^{16,17}$ PRNT and conventional virus isolation methods offer direct identification of dengue viruses but are time-consuming and suffer from low rates of detection. ${ }^{18}$ Virus culture is also expensive and often requires expertise and equipment that are 
not always available where they are most needed. It has also been suggested that successful isolation of dengue viruses from the serum of infected patients is sometimes difficult because of the presence of high titred cross-reactive antibodies. ${ }^{18}$ DNA probe hybridisation is a relatively sensitive method for the detection of viral genomes and has been applied to the detection, typing and measurement of dengue virus RNA. ${ }^{6,7}$ Even so, it is laborious and crosshybridisation has been reported between dengue type 2 and type 4 in cDNA slot blot hybridisation. ${ }^{7}$

The specificity of our PCR amplification of the dengue viral genome was indicated by the restriction endonuclease digestion analysis and by Southern blotting hybridisation with oligonucleotides representing the central portion of the amplified viral genome. Thus, the specificity of our analysis relies not only on the amplification of fragments of predicted sizes but also on the ability of the amplified products to generate restriction endonuclease DNA fragments of correct sizes and to hybridise with specific oligonucleotide probes. Results suggest that our PCR protocols not only have high specificity for dengue virus but also are able to determine the types of dengue viruses. The ability of PCR for typing may be very useful since antigenic and genetic heterogeneities have been shown to exist among different isolates or strains of dengue viruses. ${ }^{19}$ Results of this study also indicate that the sensitivity of the PCR method compares very favourably with either conventional virus isolation or serological analysis.

The results presented here suggest that the PCR DNA amplification method is rapid, specific and sensitive and may prove useful for detecting dengue viruses in clinical specimens. It may also find a place in the surveillance of dengue viral activity in vectors and in epidemiological field specimens in which the concentrations of virus may be low.

(This study was supported by Medical Research Grant CMRP-286 from Chang Gung Medical College and Memorial Hospital, and by Research Grant NSC79-O4I 2-B $182-$ 02 from the National Science Council, Republic of China, awarded to C.C.P. The authors acknowledge the technical assistance of Mr Chuan-Liang Kao, Dr Wei-Jung Chen, Ms Chia-Chi Ku and Ms Li-Jung Chien. The authors also acknowledge the encouragement and support of Dr Delon Wu and Dr Chau-Hsiung Chang.)

\section{References}

I. Halstead SB. Pathogenesis of dengue: challenges to molecular biology. Science 1988; 239: $476-480$.

2. Halstead SB. Selected primary health care: strategies for control of disease in the developing world. XI. Dengue. Rev Infect Dis 1987; 6: 25I-264.

3. Tesh RB. A method for the isolation and identification of dengue viruses, using mosquito cell cultures. Am f Trop Med Hyg 1979; 28: 1053-1059.

4. Kuberski TT, Rosen L. A simple technique for the detection of dengue antigen in mosquitoes by immunofluorescence. Am f Trop Med Hyg 1977; 26: 533-537.

5. Henchal EA, McCown JM, Seguin MC, Gentry MK, Brandt WE. Rapid identification of dengue virus isolates by using monoclonal antibodies in an indirect immunofluorescence assay. Am $\mathcal{F}$ Trop Med Hyg I983; 32: 164-I69.

6. Kerschner JA, Vorndam AV, Monath TP, Trent DW. Genetic and epidemiological studies of dengue type 2 viruses by hybridization using synthetic deoxyoligonucleotides as probes. f Gen Virol I986; 67 : 2645-2661. 
7. Henchal EA, Narupiti S, Feighny R, Padmanabhan R, Vakharia V. Detection of dengue virus RNA using nucleic acid hybridization. $f$ Virol Methods 1987 ; $15:$ I87-200.

8. Saiki SK, Gelfand DH, Stoffel S et al. Primer-directed enzymatic amplification of DNA with a thermostable DNA polymerase. Science I988; 239: 487-49I.

9. Eisenstein BI. The polymerase chain reaction: a new method of using molecular genetics for medical diagnosis. $N$ Engl $\mathcal{F}$ Med I990; 322: I78-183.

Io. Chomczynski P, Sacchi N. Single-step method of RNA isolation by acid guanidium thiocyanate-phenol-chloroform extraction. Anal Biochem I987; 162: 156-I 59.

II. Mason PW, McAda PC, Mason TL, Fournier MJ. Sequence of the dengue-I virus genome in the region encoding the three structural proteins and the major nonstructural protein NS I. Virology 1987; 161: 262-267.

I2. Yaegashi T, Vakhari VN, Page K, Sasaguri Y, Feighny R, Padmanabhan R. Partial sequence analysis of cloned dengue virus 2 genome. Gene $1986 ; 46: 257-267$.

13. Maniatis T, Fritsch EF, Sambrook J (Eds) Molecular cloning : a laboratory manual. Cold Spring Harbor, N.Y.: Cold Spring Harbor Laboratory, I982.

I4. Pao CC, Lin SS, Lin CY, Maa JS, Lai CH, Hsieh TT. Identification of human papillomavirus DNA sequences in peripheral blood mononuclear cells. Am $\mathcal{F}$ Clin Pathol I991; $95: 540-546$.

I5. Sarkar G, Sommer SS. Shedding light on PCR contamination. Nature I990; 343: 27.

I6. Henchal EA, Putnak JR. The dengue viruses. Clin Microbiol Rev r990; 3: 376-396.

17. Innis BL, Nisalak A, Nimmannitya $S$ et al. An enzyme-linked immunosorbent assay to characterize dengue infections where dengue and Japanese encephalitis co-circulate. $A m \mathcal{F}$ Trop Med Hyg 1989; 40:418-427.

I8. Waterman SH, Kuno G, Gubler DJ, Sather GE. Low rates of antigen detection and virus isolation from the peripheral blood leukocytes of dengue fever patients. Am $\mathcal{F}$ Trop Med Hyg $1985 ; 34: 380-384$.

19. Trent DW, Grant JA, Rosen L, Monath TP. Genetic variation among dengue 2 viruses of different geographic origin. Virology $1983 ; \mathbf{1 2 8}: 27 \mathbf{I}-284$. 